Santa Clara University

Scholar Commons

Communication

College of Arts \& Sciences

$8-2008$

\title{
Social Exchange Orientation and Conflict Communication in Romantic Relationships
}

Justin P. Boren

Santa Clara University, jboren@scu.edu

Amy M. Bippus

Sabrina Worsham

Follow this and additional works at: http://scholarcommons.scu.edu/comm

Part of the Communication Commons

\section{Recommended Citation}

Bippus, A. M., Boren, J. P., Worsham, S. (2008). Social exchange orientation and conflict communication in romantic relationships. Communication Research Reports, 25(3), 227-234. doi: 10.1080/08824090802237584

http://dx.doi.org/10.1080/08824090802237584

This Article is brought to you for free and open access by the College of Arts \& Sciences at Scholar Commons. It has been accepted for inclusion in Communication by an authorized administrator of Scholar Commons. For more information, please contact rscroggin@scu.edu. 


\title{
Social Exchange Orientation and Conflict Communication in Romantic Relationships
}

\author{
Amy M. Bippus, Justin P. Boren, \& Sabrina Worsham
}

Prior research has not conclusively established how individuals' social exchange orientation (EO) affects their communication in, and satisfaction with, romantic relationships. Surveying 466 individuals in romantic relationships, we found that concern about being underbenefitted was more strongly correlated with conflict behaviors than concern about overbenefittedness, and that conflict communication influenced the relationship between exchange orientation and relationship satisfaction. We discuss the need for further research to discover how EO may influence communication patterns as relationships develop.

Keywords: Conflict; Conflict Tactics; Relationship Satisfaction; Romantic Relationships; Social Exchange Orientation

People inevitably bring expectations into their relationships, such as their notions of fairness and the contributions that partners should make. The current investigation explored how these preconceived attitudes affect participants' ways of interacting with their partners. Specifically, we focused on how partners' own orientation toward social exchange is associated with their communication about conflict issues in their relationships. We also tested whether one's own conflict communication influences the association between one's EO and relational satisfaction.

Amy M. Bippus ( $\mathrm{PhD}$, University of Texas) is an associate professor at the Department of Communication Studies, California State University, Long Beach, California, USA. Justin P. Boren (MA, California State University, Long Beach) is a doctoral student at the Hugh Downs School of Human Communication, Arizona State University, Tempe, Arizona, USA. Sabrina Worsham (MA, California State University, Long Beach) is a doctoral student in the Department of Speech Communication, Southern Illinois University, Carbondale, Illinois, USA. Correspondence: Amy M. Bippus, Department of Communication Studies, California State University, Long Beach, 1250 Bellflower Blvd., Long Beach, CA 90840. Tel.: (562) 985-7862; Fax: (562) 9854259; E-mail: abippus@csulb.edu. 
Exchange occurs when one individual in the relationship provides material or emotional commodities to the other with an expectation of return of such rewards (Buunk \& Prins, 1998). Canary and Stafford (2007) claimed that relational partners are most satisfied when the give-and-take in daily life is perceived as equal. Molm, Schaefer, and Collett (2007) noted that the significance of reciprocal exchanges is not limited to the instrumental value of the benefits received, but includes the symbolic social solidarity between the exchange partners that is conveyed in the act of reciprocity.

Murstein, Cerreto, and MacDonald (1977) argued that people vary in the degree to which they are attentive to costs and benefits in relationships. At one end of the continuum are "exchange-oriented" (EO) individuals, who "keep score" and want to repay their partners for positive or negative actions within the relationship. On the other end are "non-exchange oriented" (NEO) individuals, who are unconcerned with "keeping score" and repayment. Sprecher (1992) proposed that these EO types are not diametrically opposed. An underbenefitted exchange orientation (UEO) reflects concern about having higher input into the relationship, such as managing a larger portion of the household chores. Overbenefitted exchange orientation (OEO) reflects concern about receiving more rewards while giving fewer to one's partner.

The various conceptualizations of EO have produced mixed results regarding the association between exchange orientation and relationship quality. Murstein et al. (1977) found a significant negative effect on marital adjustment when both partners are highly exchange-oriented. Sprecher (1998) found that an underbenefitted exchange orientation (UEO) is only slightly negatively correlated to relationship quality. Dainton (2003) observed that UEO, and to a lesser extent OEO, were negatively associated with relational satisfaction, suggesting that any attention to inequity may have deleterious effects on individuals' experiences in their romantic relationships.

Murstein and colleagues (1977) argued that, beyond relationship satisfaction, exchange orientation influences people's behavior in their relationships. In essence, having expectations about benefit exchange in one's relationships may evoke behaviors to deal with inequity; this may better explain variations in satisfaction than exchange orientation by itself. Studying daily social support in couples, Iida, Shrout, Seidman, Fujita, and Bolger (2008) found that people were much more likely to provide social support to their partners when they had received support from their partners, reflecting attention to reciprocity. Similarly, Gleason, Iida, Bolger, and Shrout (2003) observed that receiving support without reciprocating was related to negative mood, suggesting sensitivity to overbenefittedness.

There is less research into specific communication behaviors as they relate to individuals' exchange orientation. While Sprecher (1992) assessed the effect of EO on "reactions to inequity," these behaviors consisted of emotional and global reactions (e.g., "decrease what I contribute to the relationship"). In a more direct test of negotiation of inequity, Kluwer, Heesink, and Van De Vliert (1997) found that spouses' discontent about the division of household labor predicted both wife demand/husband withdraw and husband demand/wife withdraw interaction 
patterns. Frisco and Williams (2003) observed that conflict about housework inequality between spouses was negatively associated with happiness and positively related to divorce. However, the exchange orientations of partners were not assessed in either study. In one study that directly assessed OEO and UEO, Dainton (2003) found that both exchange orientations were negatively associated with the conflict management and positivity relational maintenance strategies.

Based on the theoretical foundations and prior research findings about exchange orientation, people high in EO should manifest their concerns in their approach to conflict. Individuals who are comfortable with their relationships being inequitable may be comparatively unmotivated to enact active problem solving strategies, and may avoid conflict altogether because they do not perceive that they stand to gain from it. However, individuals who are high in OEO or UEO and are not comfortable with inequity may be motivated to deal with conflict in different ways. For instance, those who are sensitive to being overbenefitted might be expected to "display behavior that is altruistic and caring" (Sprecher 1998, p. 221), perhaps involving conflict engagement strategies; alternatively, they may be reluctant to actively engage in conflict with partners for fear of potentially worsening the inequity. On the other hand, people high in UEO may be skeptical of their prospects for bringing about change, leading them to disengage from conflict with partners. Thus, both UEO and OEO may be linked to tendencies to both engage and disengage from conflict with partners. Indeed, Dainton (2003) found that both perceived underbenefittedness and overbenefittedness in one's relationship were negatively associated with integrative conflict management. The first research question addressed the links between each exchange orientation and conflict management strategies.

RQ1: How are UEO and OEO associated with conflict tactics?

The degree to which people's EO affects their relationship may be influenced by the communication they have with their partners to manage their equity concerns. This may explain the mixed findings of prior research regarding the link between EO and relationship quality, in that people's attitudes toward inequity are less important than the strategies they use to address it. To investigate this possibility, the following research question was posed:

RQ2: How do people's conflict behaviors in their relationship influence the association between $E O$ and relationship satisfaction?

\section{Method}

\section{Participants}

Respondents $(N=466$; males $n=175$; females $n=291)$ were solicited in business and humanities courses at a large urban university. The average age of participants was 21.54 years $(S D=4.45)$, and most classified themselves as Euro-American (36.5\%), followed by Asian American (21.5\%), Latino/a American (19.1\%), African American (4.1\%), and Native American (0.4\%). Eighty-three individuals identified 
themselves as "other" and 3 did not indicate their ethnicity. Data were collected from only one partner in the relationship. The mean reported age for their partners was $22.81(S D=6.07)$. The median length of the relationships between respondents and their partners was 56 weeks, or about 13 months. Most of the relationships were heterosexual $(97.2 \%)$ and most of the couples were unmarried $(95.9 \%)$ and not living together $(91 \%)$.

\section{Measures}

Respondents' exchange orientation was assessed with Sprecher's (1998) twodimensional measure, with 19 items representing an underbenefitted orientation ( $\alpha=.85$, per-item $M=4.74, S D=1.20$ ), and 17 items representing an overbenefitted orientation $(\alpha=.81$, per-item $M=6.68, S D=.97)$. Relationship satisfaction was measured with the Relationship Assessment Scale (Hendrick, Dicke, \& Hendrick, 1998, $\alpha=.90$, per-item $M=7.04, S D=1.5)$. The Conflict Tactics Questionnaire (Canary, Cunningham, \& Cody, 1988) assessed respondents' conflict behavior in the most recent conflict they had with their partner. Eight items assessed Avoidance $(\alpha=.80$, per-item $M=3.23, S D=1.91)$; ten measured Integration $(\alpha=.91$, peritem $M=6.32, S D=1.17)$; four items each assessed Criticism $(\alpha=.90$, per-item $M=4.15, S D=2.16)$ and Anger $(\alpha=.80$, per-item $M=3.65, S D=1.97)$; and two items measured Denial ( $\alpha=.80$, per-item $M=3.20, S D=2.15$ ).

In a check for potential confounding variables, we found that age and length of time in the relationship were not significantly correlated with any of the variables in our analyses. One significant sex difference emerged: women $(M=6.49)$ were more likely to use integrative conflict tactics than were men $(M=5.80)$. Given this single finding and in the interest of preserving statistical power, we did not control for sex in subsequent analyses.

\section{Results}

The first research question asked how individuals' degree of underbenefitted orientation (UEO) and overbenefitted orientation (OEO) are associated with conflict tactics in a recent conflict with their romantic partner. UEO was significantly and positively related to the conflict engagement strategies of Criticism, $r(441)=.37$, $p<.001, r^{2}=.14$, and Anger, $r(437)=.28, p<.001, r^{2}=.08$, but negatively associated with Integration, $r(435)=-.11, p<.03, r^{2}=.01$. UEO was also positively associated with the disengagement tactics of Avoidance, $r(439)=.22, p<.001$, $r^{2}=.05$, and Denial, $r(442)=.20, p<.001, r^{2}=.04$. Alternatively, OEO was significantly and positively related to Integration, $r(440)=.25, p<.001, r^{2}=.06$, and inversely associated with Avoidance, $r(444)=-.17, \mathrm{p}<.001, r^{2}=.03$, Anger, $r(443)=-.12, p<.05, r^{2}=.01$, and Denial, $r(447)=-.16, p<.001, r^{2}=.03$. The correlation between $\mathrm{OEO}$ and Criticism was not significant, $r(446)=.00$, $n s$ (see Table 1). 
Table 1 Correlation Matrix of Exchange Orientation, Conflict, and Relationship Satisfaction Variables

\begin{tabular}{lcccccccc}
\hline & UEO & OEO & Ang & Avo & Crit & Den & Int & RelSat \\
\hline Underbenefitted & & & & & & & & \\
$\quad$ Exchange orientation & - & $.18^{\dagger}$ & $.28^{\dagger}$ & $.22^{\dagger}$ & $.37^{\dagger}$ & $.19^{\dagger}$ & $-.11^{*}$ & $-.19^{\dagger}$ \\
Overbenefitted & & & & & & & & \\
$\quad$ Exchange orientation & $.18^{\dagger}$ & - & $-.12^{*}$ & $-.17^{\dagger}$ & .00 & $-.16^{\dagger}$ & $.25^{\dagger}$ & .09 \\
Anger & $.28^{\dagger}$ & $-.12^{*}$ & - & $.27^{\dagger}$ & $.61^{\dagger}$ & $.23^{\dagger}$ & $-.28^{\dagger}$ & $-.20^{\dagger}$ \\
Avoidance & $.22^{\dagger}$ & $-.17^{\dagger}$ & $.27^{\dagger}$ & - & $.36^{\dagger}$ & $.60^{\dagger}$ & $-.27^{\dagger}$ & $-.30^{\dagger}$ \\
Criticism & $.37^{\dagger}$ & $.00^{\dagger}$ & $.61^{\dagger}$ & $.36^{\dagger}$ & - & $.26^{\dagger}$ & $-.18^{\dagger}$ & $-.24^{\dagger}$ \\
Denial & $.19^{\dagger}$ & $-.16^{\dagger}$ & $.23^{\dagger}$ & $.60^{\dagger}$ & $.26^{\dagger}$ & - & -.08 & $-.17^{\dagger}$ \\
Integration & $-.11^{*}$ & $.25^{\dagger}$ & $-.28^{\dagger}$ & $-.28^{\dagger}$ & $-.18^{\dagger}$ & -.08 & - & $.26^{\dagger}$ \\
$\quad$ Relationship satisfaction & $-.19^{\dagger}$ & .09 & $-.20^{\dagger}$ & $-.30^{\dagger}$ & $-.24^{\dagger}$ & $-.17^{\dagger}$ & $.26^{\dagger}$ & - \\
\hline
\end{tabular}

* Significant at the $p<.05$.

${ }^{\dagger}$ Significant at the $p<.001$ level.

The second research question probed how people's conflict behaviors influence the association between exchange orientation and relationship satisfaction. Following Baron and Kenny's (1986) guidelines, the mediation model for each of the exchange orientation and conflict variables was calculated separately, by first regressing the relationship satisfaction on the independent variable, then each mediator on the independent variable, then relationship satisfaction on each mediator, and finally relationship satisfaction on both the independent variable and each mediator. Sobel's (1982) test was used to establish whether the association between the independent variable and the dependent variables was significantly reduced when accounting for the effect of the mediator.

UEO was significantly and negatively associated with relationship satisfaction $(b=-.23, S E=.06, \beta=-.19, p<.001)$. There was a significant positive relationship between UEO and each of the mediators: Anger $(b=.46, S E=.08, \beta=.28$, $p<.001)$, Avoidance $(b=.36, S E=.07, \beta=.22, p<.001)$, Criticism $(b=.66$, $S E=.08, \beta=.37, p<.001)$, Denial $(b=.34, S E=.08, \beta=.19, p<.001)$, and Integration $(b=-.10, S E=.05, \beta=-11, p<.05)$. Each of the mediators was also significantly correlated with relationship satisfaction: Anger $(b=-.15, S E=.04$, $\beta=-.20, p<.001)$, Avoidance $(b=-.23, S E=.04, \beta=-.30, p<.001)$, Criticism $(b=-.17, S E=.03, \beta=-.24, p<.001)$, Denial $(b=-.12, S E=.03, \beta=-.17$, $p<.001)$, and Integration $(b=.34, S E=.06, \beta=.26, p<.001)$.

Finally, all of the conflict variables emerged as mediators of the relationship between UEO and relationship satisfaction. When UEO and Anger were entered into the model together, both UEO $(b=-.23, S E=.06, p<.005)$ and Anger $(b=-.12$, $S E=.04, \beta=-.14, p<.005)$ remained significant predictors, and the association between UEO and relationship satisfaction was reduced from $\beta=-.19$ to $\beta=-.15(z=-2.79, p<.01)$. Both UEO $(b=-.15, S E=.06, p<.01)$ and 
Avoidance $(b=-.19, S E=.04, \beta=-.25, p<.001)$ remained significant predictors, with a reduction in UEO's effect to $\beta=-.12(z=-3.52, p<.001)$. UEO $(b=-.14$, $S E=.06, p<.05)$ and Criticism $(b=-.14, S E=.03, \beta=-.20, p<.001)$ were significantly associated with relationship satisfaction, reducing the effect of UEO to $\beta=-.11(z=-3.71, p<.001)$. Together, UEO $(b=-.20, S E=.06, p<.005)$ and Denial $(b=-.08, S E=.03, \beta=-.12, p<.05)$ were significant predictors, with a significant reduction in the effect of UEO $(\beta=.12)(z=-2.12, p<.05)$. Finally, UEO $(b=-.20, S E=.06, p<.001)$ and Integration $(b=.29, S E=.06, \beta=.22$, $p<.001)$ were significant predictors in the model together, with a slight reduction in the effect of UEO $(\beta=-.17)(z=-2.03, p<.05)$, indicating that Integration partially mediated the effect of UEO on relationship satisfaction.

Regressing relationship satisfaction on OEO yielded a non-significant relationship $(b=.14, S E=.07, \beta=.09, p=.06$ ). However, the same procedure was followed as with UEO to uncover possible suppressor variables among the mediators. No significant changes in the effect of OEO on relationship satisfaction were revealed by the inclusion of any of the mediator variables in the model.

\section{Discussion}

These results paint an interesting picture about how people's attitudes toward the exchange of resources and services are related to their feelings about, and behavior in, their romantic relationships. The data reflected higher mean OEO scores than UEO scores, indicating that people are more concerned about getting less than they deserve from others than that they may be giving less than is warranted. Cohen (1992) characterizes $r=.10$ as a small effect size, and $r=.30$ as a medium effect size. Though many of our effect sizes were small, others were moderately robust and suggest that inequity concerns do, in fact, manifest themselves in relational interactions.

We found that sensitivity to underbenefittedness and overbenefittedness are predictive of one's conflict behaviors, but in notably different ways. In terms of specific strategies used in a recent conflict, concern about being underbenefitted was associated with having engaged in criticism of one's partner, expressing anger toward him or her, and having denied or avoided conflict; it was also negatively linked to the use of integrative tactics (though this effect was small). Thus, it seems that sensitivity to being underbenefitted in one's exchange relationships is associated with a tendency to approach conflict aggressively in one's romantic relationship, or avoid it altogether. It may be that concern about being underbenefitted is linked to people actively showing their dissatisfaction about issues which they deem important, but resisting partner demands (which might increase the "trade deficit") with criticism and avoidance. On the other hand, OEO was positively associated with the use of integrative conflict tactics and negatively associated with expressing anger, avoiding, or denying the conflict. That is, the degree to which people are sensitive to getting more than their rightful share of rewards in relationships was linked with having chosen to actively seek mutually satisfying solutions and refraining from avoiding 
responsibility in conflict. While the effect sizes for OEO were small, these findings support the idea that concerns about being more benefitted than others may be associated with people choosing productive strategies in conflict.

The findings regarding the link between exchange orientation and relational satisfaction provide additional texture to the mixed results reported in prior studies. We found that both concern about being underbenefitted and overbenefitted influenced relationship satisfaction, but the association between UEO and relationship satisfaction was partially mediated by conflict behaviors. The conflict strategies of avoidance, criticism, and denial in particular were shown to partially mediate the relationship between people's concerns about being underbenefitted and their perceptions of their relational quality. In other words, people's general attitude about being underbenefitted in their relationships was linked to their relational quality with their romantic partner directly, but also indirectly through their effect on how people communicatively managed such issues in their romantic relationship. Given the cross-sectional nature of our data, these results should be considered tentatively; further research using longitudinal data is necessary to affirm the directionality of these relationships.

Our sample included mostly young relationships, with the median time that the couples had been together at just over a year. We regarded this as an asset for this study, as Sprecher (1998) explicitly recommended future research focus on newly formed dating relationships to determine whether EO exerts greater influence early in relationships. However, a sample with more long-term relationships would represent a more comprehensive picture of these dynamics over the course of relationships, as would data from both partners. Moreover, studying individuals whose relationships have dissolved may provide useful comparative information on the impact of exchange orientation on relationship persistence and individuals' motives for terminating relationships.

In summary, our findings suggest that there is a complicated connection between people's equity concerns and their satisfaction with romantic partners. The way individuals communicate about issues of conflict with their partners seems to be an important factor in understanding this link. It appears that one's own attitudes about relational equity are not insurmountable obstacles in romantic relationships, but are linked with how we choose to negotiate the inevitable give and take within them.

\section{References}

Baron, R. M., \& Kenny, D. A. (1986). The moderator-mediator variable distinction in social psychological research: Conceptual, strategic and statistical considerations. Journal of Personality and Social Psychology, 51, 1173-1182.

Buunk, B. P., \& Prins, K. S. (1998). Loneliness, exchange orientation, and reciprocity in friendships. Personal Relations, 5, 1-14.

Canary, D. J., Cunningham, E. M., \& Cody, M. J. (1988). Goal types, gender, and locus of control in managing interpersonal conflict. Communication Research, 15, 426-446.

Canary, D., \& Stafford, L. (2007). People want — and maintain — fair marriages: Reply to Ragsdale and Brandau-Brown. Journal of Family Communication, 7(1), 61-68.

Cohen, J. A. (1992). A power primer. Psychological Bulletin, 112, 155-159. 


\section{A. M. Bippus et al.}

Dainton, M. (2003). Equity and uncertainty in relational maintenance. Western Journal of Communication, 67(2), 164-186.

Frisco, M. L., \& Williams, K. (2003). Perceived housework equity, martial happiness and divorce in dual-earner households. Journal of Family Issues, 24, 51-73.

Gleason, M. E. J., Iida, M., Bolger, N., \& Shrout, P. E. (2003). Daily supportive equity in close relationships. Personality and Social Psychology Bulletin, 29(6), 1036-1045.

Hendrick, S. S., Dicke, A., \& Hendrick, C. (1998). The relationship assessment scale. Journal of Social and Personal Relationships, 15, 137-142.

Iida, M., Shrout, P., Seidman, G., Fujita, K., \& Bolger, N. (2008). Modeling support provision in intimate relationships. Journal of Personality \& Social Psychology, 94(3), 460-478.

Kluwer, E. S., Heesink, J. A. M., \& Van De Vliert, E. (1997). The marital dynamics of conflict over the division of labor. Journal of Marriage \& the Family, 59, 635-653.

Molm, L., Schaefer, D., \& Collett, J. (2007). The value of reciprocity. Social Psychology Quarterly, 70(2), 199-217.

Murstein, B. I., Cerreto, M., \& MacDonald, M. G. (1977). A theory and investigation of the effect of exchange-orientation on marriage and friendship. Journal of Marriage and the Family, 39, 543-548.

Sobel, M. E. (1982). Asymptotic confidence intervals for indirect effects in structural equation models. In S. Leinhart (Ed.), Sociological methodology 1982 (pp. 290-312). San Francisco: Jossey-Bass.

Sprecher, S. (1992). How men and women expect to feel and behave in response to inequity in close relationships. Social Psychology Quarterly, 55(1), 57-69.

Sprecher, S. (1998). The effect of exchange orientation on close relationships. Social Psychology Quarterly, 61(3), 220-231. 
Copyright of Communication Research Reports is the property of Eastern Communication Association and its content may not be copied or emailed to multiple sites or posted to a listserv without the copyright holder's express written permission. However, users may print, download, or email articles for individual use. 